\title{
Trends in aortic clamp use during coronary artery bypass surgery: Effect of aortic clamping strategies on neurologic outcomes
}

\author{
William T. Daniel III, BS, Patrick Kilgo, MS, John D. Puskas, MD, Vinod H. Thourani, MD, \\ Omar M. Lattouf, MD, PhD, Robert A. Guyton, MD, and Michael E. Halkos, MD, MSc
}

Objective: The purpose of the present study was to determine the effect of different clamping strategies during coronary artery bypass grafting on the incidence of postoperative stroke.

\begin{abstract}
Methods: In the present case-control study, all patients at Emory hospitals from 2002 to 2009 with postoperative stroke after isolated coronary artery bypass grafting $(n=141)$ were matched $1: 4$ to a contemporaneous cohort of patients without postoperative stroke $(\mathrm{n}=565)$. The patients were matched according to the Society of Thoracic Surgeons' predicted risk of postoperative stroke score, which is based on 26 variables. The patients who received on-pump and off-pump coronary artery bypass grafting were matched separately. Multiple logistic regression analysis with adjusted odds ratios was performed to identify the operative variables associated with postoperative stroke.
\end{abstract}

Results: Among the on-pump cohort, the single crossclamp technique was associated with a decreased risk of stroke compared with the double clamp (crossclamp plus partial clamp) technique (odds ratio, $0.385 ; P=.044$ ). Within the on-pump cohort, no significant difference was seen in the incidence of stroke according to clamp use. Epiaortic ultrasound of the ascending aorta increased from $45.3 \%$ in 2002 to $89.4 \%$ in 2009. From 2002 to 2009 , clamp use decreased from $97.7 \%$ of cases to $72.7 \%$.

Conclusions: During on-pump coronary artery bypass grafting, the use of a single crossclamp compared with the double clamp technique decreased the risk of postoperative stroke. The use of any aortic clamp decreased and epiaortic ultrasound use increased from 2002 to 2009, indicating a change in the operative technique and surgeon awareness of the potential complications associated with manipulation of the aorta. (J Thorac Cardiovasc Surg $2014 ; 147: 652-7)$

Coronary artery bypass grafting (CABG) is the most commonly performed operation by cardiothoracic surgeons. Postoperative stroke is a rare but major cause of morbidity and mortality in patients undergoing CABG. Several operative techniques have been used in attempts to minimize the detrimental morbidity and mortality associated with postoperative stroke. Because increased ascending aortic manipulation has been proposed as the primary mechanism of postoperative cerebral atheroembolism, the focus has concentrated on innovative techniques to minimize manipulation of the ascending aorta.

\footnotetext{
From the Clinical Research Unit, Division of Cardiothoracic Surgery, Emory University School of Medicine, Atlanta, Ga.

This study was supported by the National Center for Advancing Translational Sciences of the National Institutes of Health (award UL1TR000454). The content is solely the responsibility of the authors and does not necessarily represent the official views of the National Institutes of Health.

Disclosures: Authors have nothing to disclose with regard to commercial support.

Received for publication Nov 7, 2012; revisions received Jan 10, 2013; accepted for publication Feb 12, 2013; available ahead of print March 13, 2013.

Address for reprints: Michael E. Halkos, MD, MSc, FACC, FACS, Division of Clinical Research Unit, Division of Cardiothoracic Surgery, Emory University School of Medicine, 550 Peachtree St, NE, Medical Office Tower, 6th Fl, Emory University Hospital-Midtown, Atlanta, GA 30308 (E-mail: mhalkos@emory.edu).

0022-5223/\$36.00

Copyright (c) 2014 by The American Association for Thoracic Surgery

http://dx.doi.org/10.1016/j.jtcvs.2013.02.021
}

Postoperative stroke occurs in approximately $2 \%$ of CABG cases. ${ }^{1,2}$ Survival among CABG patients at both 1 and 5 years has been significantly reduced in patients who have had a postoperative stroke compared with those who have not. ${ }^{3}$ Furthermore, postoperative stroke is also a major source of increased healthcare costs. Compared with those without a postoperative stroke, an additional $\$ 19,000$ in hospital costs have been attributed to patients with a postoperative stroke. ${ }^{4}$ Moreover, in patients with a postoperative stroke and 2 or more complications, more than $\$ 58,000$ in additional hospital costs has been reported. ${ }^{4}$

Most CABG procedures in the United States are performed with cardiopulmonary bypass support. Two different clamping strategies have been used for the construction of the proximal aortocoronary anastomoses: single clamping or double clamping. With off-pump coronary artery bypass $(\mathrm{OPCAB})$, a partial clamp is frequently used for construction of the proximal anastomoses. However, a clampless approach is possible with facilitating devices (Heartstring; Maquet Cardiovascular, San Jose, Calif) or anastomotic connectors. These devices can be selectively deployed on relatively disease-free portions of the aorta to minimize the risk of atheroembolism. Therefore, the purpose of the present study was to test the hypothesis that aortic clamping was associated with an increased risk of stroke. Furthermore, we wanted to determine the effect of the 


\section{Abbreviations and Acronyms \\ $\mathrm{CABG}=$ coronary artery bypass grafting \\ $\mathrm{ONCAB}=$ on-pump coronary artery bypass \\ OPCAB $=$ off-pump coronary artery bypass \\ PROPS = predicted risk of postoperative stroke \\ STS $\quad$ Society of Thoracic Surgeons}

different clamping strategies used for performing proximal anastomoses on the incidence of postoperative stroke.

\section{METHODS \\ Patients}

The Emory University's institutional Society of Thoracic Surgeons (STS) Adult Cardiac Database was queried for all patients (cases) with postoperative stroke after isolated, primary CABG. The control patients were selected from the entire cohort without postoperative stroke. All consecutive patients from January 1, 2002 to December 31, 2009 were included in the database query.

\section{Design}

The present study was a retrospective, single-center, case-control study. A case-control study design was chosen because the operative details of the aortic clamping methods are not currently available in the STS database. The operative reports were reviewed and detailed data collected about the surgical strategy, including an on-pump or off-pump approach, details about the aortic clamping methods, and the extent of aortic atherosclerosis measured using epiaortic ultrasound. These data were then merged with the STS database to produce the complete data set. The institutional review board at Emory University, in compliance with the Health Insurance Portability and Accountability Act regulations and the Declaration of Helsinki, approved the present study. The institutional review board waived the need for individual patient consent.

\section{Exclusions}

Patients undergoing concomitant cardiac operations, redosternotomy, or emergency CABG were excluded from the study.

\section{Matching Algorithm}

A predicted risk of postoperative stroke (PROPS) score, as part of the STS database, is calculated using 26 preoperative variables believed to be associated with an increased risk of postoperative stroke. The PROPS score has been identified as a reliable predictor of postoperative stroke by Shroyer and colleagues. ${ }^{5}$ The control patients were matched to the patients in a 1:4 ratio using the PROPS score and whether the patient underwent ONCAB or OPCAB. Because the effect of an on- versus off-pump strategy on the incidence of postoperative stroke was not the goal of the present study, the use of $C A B G$ was used as part of the matching algorithm. The ONCAB control patients were matched to the ONCAB patients and the OPCAB control patients to the OPCAB patients. An optimal matching algorithm was used that was designed to identify the best cutpoint for a continuous variable. ${ }^{6}$ The optimal matching algorithm was used as a SAS macro that defined a distance measure between the patients and control patients according to the PROPS score. The control patient chosen for each case patient was the one closest to the patient in terms of the distance measure produced by the optimal matching algorithm. This algorithm sequentially matched each patient with stroke with the potential nonstroke control patients by calculating the multivariate distance between the patients using the 26 variables that constitute the PROPS. The algorithm chooses the set of matches that minimizes the sum of the multivariate distances across all possible sets of matches.

\section{Surgical Technique}

For the entire cohort, the overall effect of any aortic clamping was examined for the entire cohort. For the ONCAB patients, the 2 most common clamping strategies were the single crossclamp and double crossclamp techniques. Another on-pump CABG strategy used by the surgeons included on-pump beating heart CABG. In the present cohort, 25 patients underwent on-pump beating heart CABG; 15 of these had the proximal anastomoses performed with a partial occluding clamp and 10 with a Heartstring device. Only 1 CABG was performed under cold fibrillatory arrest. For all other on-pump cases, either a single clamp or double clamp technique was used.

For patients undergoing $\mathrm{OPCAB}$, the strategies examined in the present study were the use of a partial-occluding clamp, the use of clampless facilitating devices, and the "no-touch" technique, which involves the use of in situ arterial grafts (no aortocoronary proximal anastomoses). A "notouch" aortic technique was used in 45 OPCAB patients.

\section{Epiaortic Ultrasound}

At Emory University, all patients currently undergoing cardiac operations routinely have the aorta evaluated using epiaortic ultrasound. It has been gradually adopted since its implementation in 2002 for patients in whom a clamp is being considered, making it the current standard of care within our institution. It is the test of choice for identifying atherosclerotic lesions within the aorta, and it is superior to transesophageal echocardiography and palpation alone. ${ }^{7-9}$ Preoperative imaging with computed tomography is another option. Before the aorta is manipulated, patients undergo an epiaortic ultrasound examination to grade the amount of atherosclerotic disease within the ascending aorta according to the thickness and presence of mobile atheroma. The aorta is graded from 1 to 5: 1, normal (<2 $\mathrm{mm}$ thickness); 2, minimal disease (2-3 $\mathrm{mm}) ; 3$, moderate disease $(3-5 \mathrm{~mm}) ; 4$, severe disease $(>5 \mathrm{~mm})$; and 5 , the presence of mobile plaque within any portion of the ascending aorta.

\section{Outcome}

The incidence of postoperative stroke was the primary outcome of the present study. Stroke was defined as a new, focal, permanent neurologic deficit found on clinical examination diagnosed by an attending neurologist and confirmed with either brain computed tomography or magnetic resonance imaging. The clinical and radiologic examinations were used to differentiate stroke from transient ischemic attack or postoperative delirium.

\section{Statistical Analysis}

A conditional logistic regression analysis was performed to evaluate the effect of clamp versus no-clamp on the occurrence of postoperative stroke, controlling for matching factors (PROPS and pump) and epiaortic grade. The epiaortic grade was controlled for as both an ordinal (1, 2, 3, 4, and 5 ) and a dichotomous (1-2 vs 3-5) variable in the regression analysis. The analysis was also performed without controlling for epiaortic grade, because its use was not ubiquitous until recently. In addition, the effect of different clamping or nonclamping strategies within the ONCAB and OPCAB patients and control patients was evaluated using conditional logistic regression analysis. In the original model, which studied the association of any clamping strategy with postoperative stroke incidence, the potential preoperative confounding variables were controlled for by the matching algorithm for the PROPS score (Table 1). The effect of cardiopulmonary bypass, or an on-pump technique, as a potential confounder was also controlled for in the matching strategy, because the patients were matched separately to the control patients according to whether an on- or off-pump strategy was used. To determine whether the year of surgery 
TABLE 1. Preoperative demographic data

\begin{tabular}{lccc}
\hline & \multicolumn{2}{c}{ Postoperative stroke } & \\
\cline { 2 - 3 } \multicolumn{1}{c}{ Variable } & Yes $(\mathbf{n}=\mathbf{1 4 1})$ & No $(\mathbf{n}=\mathbf{5 6 5})$ & $\boldsymbol{P}$ value \\
\hline Age (y) & $65.7 \pm 10.6$ & $66.8 \pm 10.3$ & .65 \\
Male gender & $82(58.2)$ & $353(62.5)$ & .35 \\
Body mass index $\left(\mathrm{kg} / \mathrm{m}^{2}\right)$ & $29.0 \pm 6.9$ & $28.7 \pm 6.5$ & .62 \\
Preoperative stroke & $33(29.7)$ & $103(20.6)$ & .04 \\
Cerebrovascular disease & $44(31.2)$ & $161(28.6)$ & .54 \\
Hypertension & $127(90.1)$ & $504(89.4)$ & .81 \\
Diabetes & $70(49.7)$ & $256(45.4)$ & .36 \\
Renal insufficiency & $16(11.4)$ & $57(10.1)$ & .67 \\
History of smoking & $59(63.4)$ & $330(69.8)$ & .23 \\
Left main disease & $35(25.0)$ & $187(33.3)$ & .06 \\
Previous myocardial infarction & $50(53.8)$ & $260(55.0)$ & .83 \\
Peripheral vascular disease & $34(24.1)$ & $109(19.4)$ & .21 \\
Arrhythmia & $18(12.8)$ & $70(12.4)$ & .90 \\
PROPS score (\%) & $2.6 \pm 2.2$ & $2.6 \pm 2.2$ & .93 \\
\hline
\end{tabular}

Data presented as mean \pm standard deviation or $\mathrm{n}(\%)$. PROPS, Predicted risk of postoperative stroke.

confounded the analysis, the year was also analyzed separately in modifications of the model.

Within each subset of operative strategy (on- or off-pump), separate models were developed to determine the association of different clamping strategies on the incidence of postoperative stroke, controlling for the PROPS score and epiaortic grade. Within the ONCAB group, a double clamping strategy was compared with a single crossclamp strategy. Within the OPCAB group, a partial-clamping strategy was compared with a Heartstring-only strategy and a partial-clamping strategy was compared with a no-clamp strategy (Heartstring vs no-touch technique).

In addition to the logistic regression analysis, descriptive analyses were performed to be able to assess the trends in clamp use and the trends in risk profiles and epiaortic use. All analyses were performed using SAS, version 9.2 (SAS Institute, Cary, NC). All comparisons were made at the 0.05 alpha level.

\section{RESULTS}

The patients and control patients were selected from a total cohort of 10,054 consecutive patients who underwent primary isolated CABG at Emory University hospitals. From this cohort, 141 cases $(1.4 \%)$ of postoperative stroke were identified. From the remaining patients, 565 control patients (patients without postoperative stroke) were selected using the matching algorithm. Epiaortic ultrasound was not performed in 181 patients $(25.6 \%)$ included in the present study.

Multiple logistic regression modeling was performed with the effect of pump strategy (on- vs off-pump), PROPS score, and epiaortic grade controlled for in the model for the entire cohort (ONCAB and OPCAB patients). When the epiaortic grade was controlled for as an ordinal variable (grade $1-5)$ in the logistic regression analysis, the odds ratio for postoperative stroke was estimated at 1.19 (95\% confidence interval, 0.53-2.67) for the use of any aortic clamp. With the epiaortic grade controlled for as a dichotomous variable (low-grade, grade 1-2; high-grade, grade 3-5), the odds ratio
TABLE 2. Comparison according to pump strategy

\begin{tabular}{lll}
\hline \multicolumn{1}{c}{ Analysis* } & OR & \multicolumn{1}{c}{$\mathbf{9 5} \%$ CI } \\
\hline $\begin{array}{l}\text { On-pump double clamp (crossclamp } \\
\text { plus partial clamp) vs single clamp }\end{array}$ & 2.60 & $1.03-6.67(P=.044)$ \\
$\begin{array}{l}\text { Off-pump partial clamp vs off-pump } \\
\quad \text { Heartstring }\end{array}$ & 1.46 & $0.49-4.4$ \\
$\begin{array}{l}\text { Off-pump partial clamp vs no clamp } \\
\quad \text { (Heartstring plus no touch) }\end{array}$ & 1.21 & $0.48-3.03$ \\
\hline OR, Odds ratio; $C I$, confidence interval. *Controlled for epiaortic grade.
\end{tabular}

was $1.46(95 \%$ confidence interval $0.60-3.56)$. Because this excluded 181 patients in whom epiaortic ultrasound was not performed, the analysis was also performed without controlling for epiaortic grade to include all patients in the study. The estimated odds ratio for the latter analysis was 1.28 (95\% confidence interval 0.76-2.17).

Within the ONCAB cohort, the double-clamp technique was associated with a increased risk of postoperative stroke compared with the single crossclamp technique (odds ratio, $2.60 ; P=.044$; Table 2 ). When a history of preoperative stroke was included in the regression model, the increased risk of stroke with the double-clamp technique was increased (odds ratio, 3.29; $P=.05$ ). Within the OPCAB cohort, no difference was found between partial clamping and no clamping (Table 2).

Epiaortic ultrasound grading was performed in 525 patients $(74.4 \%)$ : $450(85.7 \%)$ had grade 1 to 2 aortic disease and $75(14.3 \%)$ had grade 3 to 5 disease (Table 3). In patients with epiaortic grade 3,4 , and 5 , a clampless technique was used in $59.5 \%, 83.3 \%$, and $93.3 \%$, respectively. In patients with epiaortic grade 1 and 2, a clampless technique was used in only $3.8 \%$ and $7.8 \%$, respectively. Epiaortic ultrasound use showed a trend for increased use from $45.3 \%$ in 2002 to $89.4 \%$ in 2009 (Figure 1). Clamp use in general showed a trend for decreased use from $97.7 \%$ in 2002 to $72.7 \%$ in 2009 (Figure 2). In the 15 patients with grade 5 aortic disease, a clampless approach was used in 14 patients; no postoperative stroke occurred among any of the grade 5 patients. Among the 114 patients with postoperative stroke who had undergone epiaortic ultrasound examinations, $70(22.2 \%)$ had grade 1 aortic disease, $27(21.1 \%)$ had grade 2, $9(21.4 \%)$ had grade 3, $4(22.2 \%)$ had grade 4 , and no patient had grade 5 aortic disease. The year of

TABLE 3. Clamp use according to epiaortic grade

\begin{tabular}{lccr}
\hline Epiaortic grade & No clamp $(\mathbf{n}=\mathbf{7 9})$ & Clamp $(\mathbf{n}=\mathbf{4 4 6})$ & Total \\
\hline 0 & $3(42.9)$ & $4(57.1)$ & 7 \\
1 & $12(3.8)$ & $303(96.2)$ & 315 \\
2 & $10(7.8)$ & $118(92.2)$ & 128 \\
3 & $25(59.5)$ & $17(40.5)$ & 42 \\
4 & $15(83.3)$ & $3(16.7)$ & 18 \\
5 & $14(93.3)$ & $1(6.7)$ & 15 \\
\hline
\end{tabular}

Data presented as n (\%). 


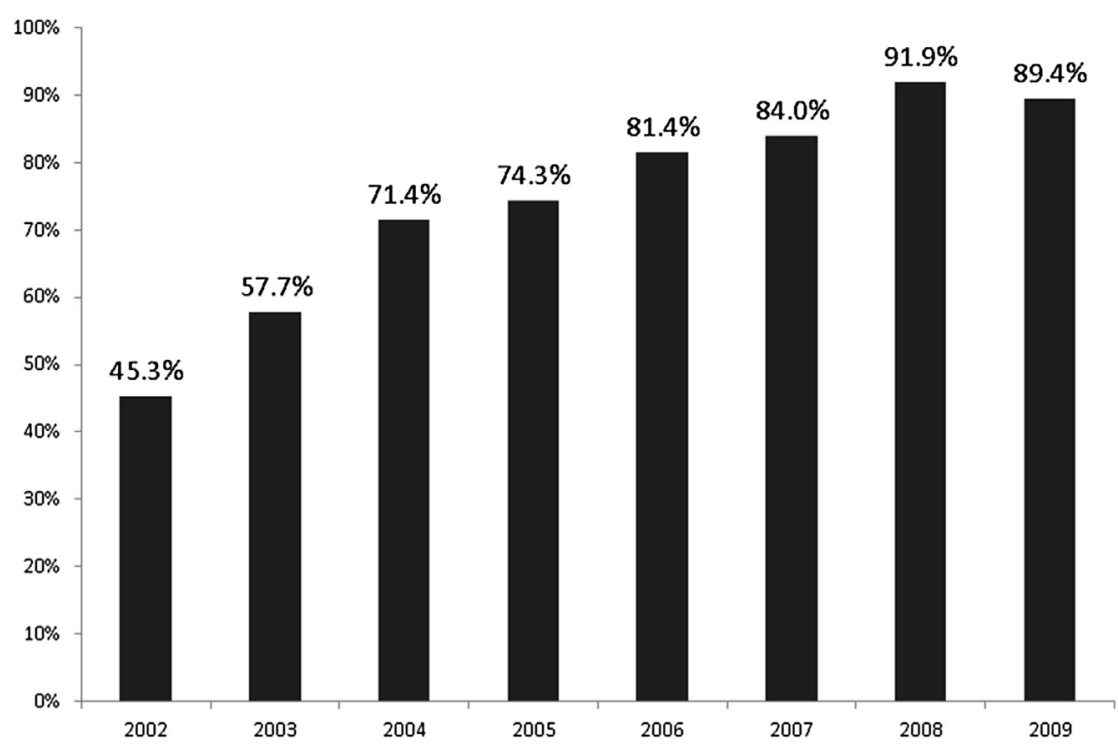

FIGURE 1. Trends in epiaortic ultrasound use at Emory University hospitals for isolated coronary artery bypass grafting.

surgery was evaluated in all analyses and was not significantly associated with the risk of postoperative stroke. Furthermore, surgeon identity was evaluated in the analysis and was also associated with the risk of postoperative stroke. The PROPS score ranged from 2.0 to 3.1 and did not significantly change during the study period.

\section{DISCUSSION}

Postoperative stroke continues to be a major complication after CABG. Although aortic manipulation remains the most important risk factor associated with postoperative stroke, other risk factors include female gender, advanced age, previous stroke, postoperative atrial fibrillation, carotid stenosis, hypertension, and diabetes. ${ }^{1,2,10-14}$ Studies have shown that $50 \%$ to $75 \%$ of all strokes after CABG are embolic $^{2}$ and are discovered within 24 hours after surgery. Through the use of transcranial Doppler ultrasonography, it has been shown that emboli are produced during aortic cannulation and clamping. ${ }^{15-19}$ Thus, minimizing aortic manipulation by eliminating cannulation and clamping might decrease the incidence of postoperative stroke by decreasing the production of emboli.

In a study by Hannan and colleagues ${ }^{20} 49,830$ patients from the New York state registry underwent risk-adjusted

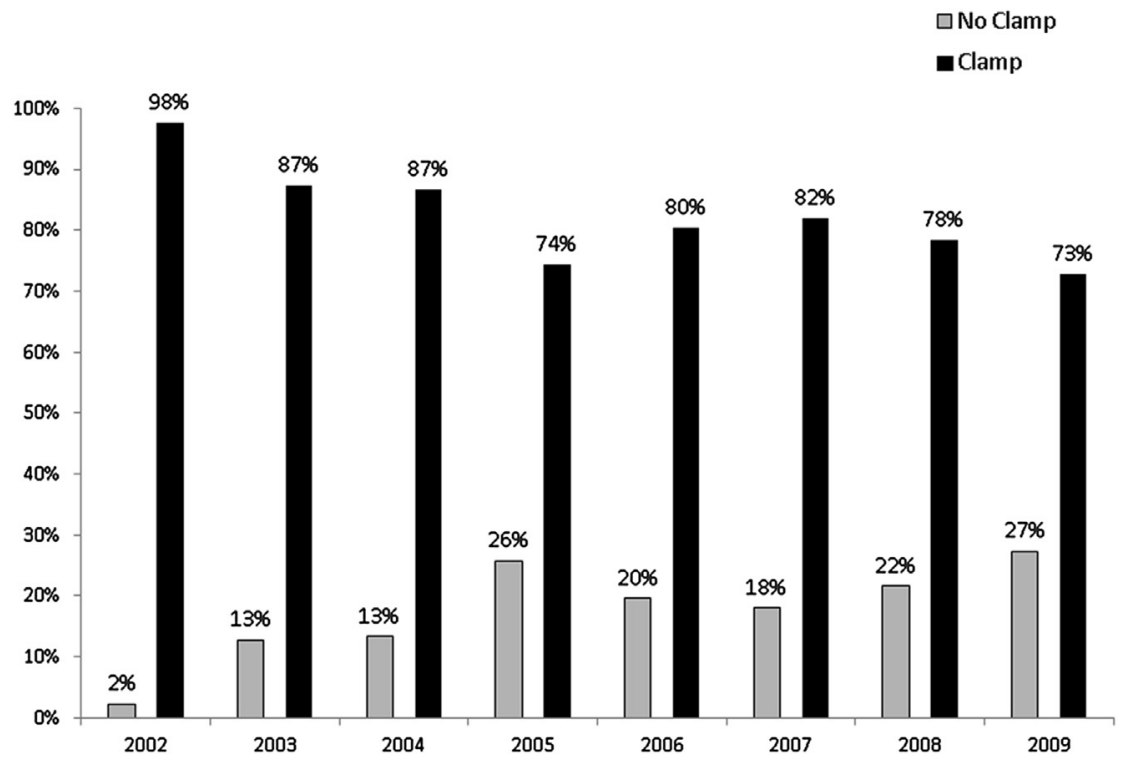

FIGURE 2. Trends in clamp use by year at Emory University hospitals for isolated coronary artery bypass grafting. 
analysis (Cox proportional hazard models and propensity analysis) comparing the outcomes after OPCAB versus ONCAB. In that study, the OPCAB patients had significantly lower 30-day mortality and a lower incidence of postoperative stroke. However, the mechanisms responsible for the observed reduction in postoperative stroke were not defined. OPCAB obviates the need for cardiopulmonary bypass; however, 2 recent meta-analyses did not show a reduction in postoperative stroke in low-risk patients. ${ }^{21,22}$ This might have been related to the use of a partial clamp on the ascending aorta during construction of the proximal anastomoses. One study did report a lower incidence of postoperative stroke in patients undergoing OPCAB without aortic manipulation compared with patients undergoing $\mathrm{OPCAB}$ with partial clamping and patients undergoing ONCAB. ${ }^{23}$ Moreover, Hammon and colleagues $^{24}$ reported a reduced incidence of postoperative neuropsychological deficits in patients undergoing single crossclamp compared with double-clamp ONCAB or patients undergoing $\mathrm{OPCAB}$ with partial clamping.

Avoiding partial clamping during construction of proximal anastomoses in OPCAB cases can be achieved by performing proximal anastomoses to in situ arterial grafts or using proximal anastomotic connectors or facilitating devices such as the Heartstring proximal anastomosis system, both of which can be performed without a partial aortic clamp. In a randomized clinical trial evaluating the PASPort proximal anastomotic connector (Cardica, Redwood City, Calif) versus construction of hand-sewn proximal anastomoses with partial clamping, all the reported strokes occurred in patients in whom an aortic clamp was used. ${ }^{25} \mathrm{In}$ previous work at our institution, we randomized 57 OPCAB patients with mild ascending aortic disease to receive either partial clamping $(n=28)$ or the Heartstring clampless device $(\mathrm{n}=29)$ for proximal graft construction on the ascending aorta. Continuous transcranial Doppler monitoring was used intraoperatively to monitor embolic signals in the middle cerebral arteries, signifying embolic events. The number of embolic signals was significantly lower in the Heartstring group than in the partial-clamping group $(50.8 \pm 36.6$ vs $90.0 \pm 64.0 ; P=.007){ }^{26}$ Two delayed clinical strokes were observed in the clamping group, with none in the Heartstring group. However, the study was not powered to detect clinically significant events. ${ }^{26}$ These preliminary data add to the growing body of evidence that minimizing aortic manipulation by avoiding an aortic clamp could be a valuable tool to reduce atheroembolic cerebral events. ${ }^{27-29}$

In the present study, the primary goal was to determine the association of clamping strategies with the incidence on postoperative stroke. Although controversial, no clear consensus has been reached on the association between the use of cardiopulmonary bypass and the incidence of postoperative stroke. Both cardiopulmonary bypass use (pump strategy) and epiaortic grade were controlled for in the analysis, because both were believed to play a role in the incidence of postoperative stroke. Because matching was done within treatment type (ie, OPCAB patients were matched to OPCAB control patients), this reduced the potential bias associated with treatment type. The main difference was that an on-pump strategy mandates at least some degree of aortic manipulation, but a strategy of minimal manipulation is possible with an off-pump approach, by either no manipulation or using clampless facilitating devices.

Overall, the aortic clamping strategy did not have a statistically significant effect on the incidence of postoperative stroke. This did not change when the epiaortic grade was controlled for either as an ordinal or a dichotomous variable or was omitted altogether from the analysis. However, within the subgroup of ONCAB patients, a significant association was found with postoperative stroke. The double clamp, on-pump strategy had a 2.5 -fold increased risk of postoperative stroke compared with the single crossclamp technique, even after controlling for epiaortic grade. Although not statistically significant, a trend was seen toward a greater risk of stroke in the patients undergoing OPCAB with a partial clamping strategy than with the no-clamp strategy.

The interpretation of these results can be explained by several limitations. Although the case-control design made data collection possible by limiting the review of operative notes to 706 patients, the sample size might have been inadequate to detect statistically significant differences among the various clamping strategies. To make this a cohort instead of a case-control study design, the operative notes of more than 10,000 patients (the sample from which this case-control study was obtained) would have required review. Because the overall incidence of postoperative stroke in the present cohort was relatively low $(<2 \%)$ detecting differences in clamping strategies was difficult. In addition, because the control patients were matched to patients with a postoperative stroke using the PROPS score, the stroke risk might have been limited to those patients with certain variables that might have place them at greater risk of stroke. Furthermore, controlling for epiaortic grade might have further limited the results, because this variable was incomplete and precluded analysis of patients who had not undergone epiaortic ultrasound. Finally, as the descriptive analyses revealed, surgeon behavior changed during the study period, which could have introduced a bias. This likely was influenced by data obtained from epiaortic scans, which undoubtedly influenced surgeon behavior. Despite controlling for stroke risk using the PROPS score, pump strategy, and epiaortic grade, it is apparent that surgeons used clamping less frequently toward the end of the study period compared with at the beginning. Furthermore, the surgeons were unlikely to use clamping methods in patients with high-grade aortas, which might have minimized the effect of aortic clamping on the incidence of stroke because these aortas were rarely clamped. This change in approach 
likely reflected a selection bias on the perceived risk of postoperative stroke associated with aortic clamping, especially in patients with advanced aortic disease found by epiaortic ultrasound. Although the risk profile of patients did not change appreciably during the study period, the use of epiaortic ultrasound and clamping did. This reflected the surgeons' belief that clamping high-grade aortas was associated with greater atheroembolic stroke risk. The lack of an increase in stroke according to epiaortic grade can be interpreted in 2 ways: (1) that the epiaortic grade does not influence the risk of stroke or (2) that the stroke incidence did not increase in higher grade aortas because changes in strategy occurred as result of the epiaortic data available with this modality of testing. An additional limitation of the present study was that the timing, etiology, and type of postoperative stroke was not defined, because this outcome was attained from the STS database.

Approximately $80 \%$ of CABG cases in the United States are performed on-pump, and the results from the present study support the use of the single crossclamp technique compared with the double clamp strategy to decrease the incidence of postoperative stroke in patients undergoing primary, isolated, nonemergent CABG. From our results, it is still unclear whether patients undergoing clamping during OPCAB have an increased risk of postoperative stroke compared with those undergoing clampless strategies. Additional research investigating the effect of clamping strategies during $\mathrm{CABG}$ or other cardiac operations could allow for continued progress to reduce the incidence of postoperative stroke after cardiac surgery.

\section{References}

1. Puskas JD, Winston AD, Wright CE, Gott JP, Brown WM, Craver JM, et al. Stroke after coronary artery operation: incidence, correlates, outcome, and cost. Ann Thorac Surg. 2000;69:1053-6.

2. Filsoufi F, Rahmanian PB, Castillo JG, Bronster D, Adams DH. Incidence, topography, predictors and long-term survival after stroke in patients undergoing coronary artery bypass grafting. Ann Thorac Surg. 2008;85:862-70.

3. Schachner T, Zimmer A, Nagele G, Hangler H, Laufer G, Bonatti J. The influence of ascending aortic atherosclerosis on the long-term survival after CABG. Eur J Cardiothorac Surg. 2005;28:558-62.

4. Brown PP, Kugelmass AD, Cohen DJ, Reynolds MR, Culler SD, Dee AD, et al. The frequency and cost of complications associated with coronary artery bypass grafting surgery: results from the United States Medicare program. Ann Thorac Surg. 2008;85:1980-6.

5. Shroyer AL, Coombs LP, Petersen ED. The Society of Thoracic Surgeons: 30-Day operative mortality and morbidity risk models. Ann Thorac Surg. 2003;75:1856-66.

6. Rosenbaum PR. Optimal matching for observational studies. JASA. 1989;84: 1024-32.

7. Bolotin G, Domany Y, de Perini L, Frolkis I, Lev-Ran O, Nesher N, et al. Use of intraoperative epiaortic ultrasonography to delineate aortic atheroma. Chest. 2005; $127: 60-5$

8. Sylivris S, Calafiore P, Matalanis G, Rosalion A, Yuen HP, Buxton BF, et al. The intraoperative assessment of ascending aortic atheroma: epiaortic imaging is superior to both transesophageal echocardiography and direct palpation. $J$ Cardiothorac Vasc Anesth. 1997;11:704-7.

9. Suvarna S, Smith A, Stygall J, Kolvecar S, Walesby R, Harrison M, et al. An intraoperative assessment of the ascending aorta: a comparison of digital palpation, transesophageal echocardiography, and epiaortic ultrasonography. J Cardiothorac Vasc Anesth. 2007;21:805-9.

10. Halkos ME, Puskas JD, Lattouf OM, Kilgo P, Guyton RA, Thourani VH. Impact of preoperative neurologic events on outcomes after coronary artery bypass grafting. Ann Thorac Surg. 2008;86:504-10.

11. Roach GW, Kanchuger M, Mangano CM, Newman M, Nussmeier N, Wolman R et al. Adverse cerebral outcomes after coronary bypass surgery: Multicenter Study of Perioperative Ischemia Research Group and the Ischemia Research and Education Foundation Investigators. N Engl J Med. 1996;335:1857-63.

12. McKhann GM, Goldsborough MA, Borowicz LM Jr, Mellits ED, Brookmeyer R, Quaskey SA, et al. Predictors of stroke risk in coronary artery bypass patients. Ann Thorac Surg. 1997;63:516-21.

13. Redmond JM, Greene PS, Goldsborough MA, Cameron DE, Stuart RS Sussman MS, et al. Neurologic injury in cardiac surgical patients with a history of stroke. Ann Thorac Surg. 1996;61:42-7.

14. Anyanwu AC, Filsoufi F, Salzberg SP, Bronster DJ, Adams DH. Epidemiology of stroke after cardiac surgery in the current era. J Thorac Cardiovasc Surg. 2007; 134:1121-7

15. van der Linden J, Casimir-Ahn H. When do cerebral emboli appear during open heart operations? A transcranial Doppler study. Ann Thorac Surg. 1991;51:237-41.

16. Blauth CI. Macroemboli and microemboli during cardiopulmonary bypass. Ann Thorac Surg. 1995;59:1300-3.

17. Barbut D, Yao FS, Lo YW, Silverman R, Hager DN, Trifiletti RR, et al. Determination of size of aortic emboli and embolic load during coronary artery bypass grafting. Ann Thorac Surg. 1997;63:1262-7.

18. Liu YH, Wang DX, Li LH, Wu XM, Shan GJ, Su Y, et al. The effects of cardiopulmonary bypass on the number of cerebral microemboli and the incidence of cognitive dysfunction after coronary artery bypass graft surgery. Anesth Analg. 2009;109:1013-22

19. Motallebzadeh R, Bland JM, Markus HS, Kaski JC, Jahangiri M. Neurocognitive function and cerebral emboli: randomized study of on-pump versus off-pump coronary artery bypass surgery. Ann Thorac Surg. 2007;83:475-82.

20. Hannan EL, Wu C, Smith CR, Higgins RS, Carlson RE, Culliford AT, et al Off-pump versus on-pump coronary artery bypass graft surgery: differences in short-term outcomes and in long-term mortality and need for subsequent revascularization. Circulation. 2007;116:1145-52.

21. Cheng DC, Bainbridge D, Martin JE, Novick RJ. Evidence-Based Perioperative Clinical Outcomes Research Group. Does off-pump coronary artery bypass reduce mortality, morbidity, and resource utilization when compared with conventional coronary artery bypass? A meta-analysis of randomized trials. Anesthesiology. 2005;102:188-203.

22. Wijeysundera DN, Beattie WS, Djaiani G, Rao V, Borger MA, Karkouti K, et al. Offpump coronary artery surgery for reducing mortality and morbidity: meta-analysis of randomized and observational studies. J Am Coll Cardiol. 2005;46:872-82.

23. Kim KB, Kang CH, Chang WI, Lim C, Kim JH, Ham BM, et al. Off-pump coronary artery bypass with complete avoidance of aortic manipulation. Ann Thorac Surg. 2002;74:S1377-82.

24. Hammon JW, Stump DA, Butterworth JF, Moody DM, Rorie K, Deal DD, et al Coronary artery bypass grafting with single cross-clamp results in fewer persistent neuropsychological deficits than multiple clamp or off-pump coronary artery bypass grafting. Ann Thorac Surg. 2007;84:1174-8.

25. Puskas JD, Halkos ME, Balkhy H, Caskey M, Connolly M, Crouch J, et al. Evaluation of the PAS-Port Proximal Anastomosis System in coronary artery bypass surgery (the EPIC trial). J Thorac Cardiovasc Surg. 2009;138:125-32.

26. El Zayat H, Puskas J, Hwang S, Thourani VH, Lattouf OM, Kilgo P, et al. Avoiding the clamp for aortocoronary proximal anastomoses is associated with fewer intraoperative cerebral embolic events: results of a prospective randomized trial Interact Cardiovasc Thorac Surg. 2012;14:12-6.

27. Wolf LG, Abu-Omar Y, Choudhary BP, Pigott D, Taggart DP. Gaseous and solid cerebral microembolization during proximal aortic anastomoses in off-pump coronary surgery: the effect of an aortic side-biting clamp and two clampless devices. J Thorac Cardiovasc Surg. 2007;133:485-93.

28. Misfeld M, Brereton RJL, Sweetman EA, Doig GS. Neurologic complications after off-pump coronary artery bypass grafting with and without aortic manipulation: meta-analysis of 11,398 cases from 8 studies. J Thorac Cardiovasc Surg. 2011;142:e11-7.

29. Emmert MY, Seifert B, Wilhelm M, Grünenfelder J, Falk V, Salzberg SP. Aortic no-touch technique makes the difference in off-pump coronary artery bypass grafting. J Thorac Cardiovasc Surg. 2011;142:1499-506. 